\title{
A ESCOLA DO FUTURO: UMA RESENHA CRÍTICA
}

\author{
THE SCHOOL OF THE FUTURE: A CRITICAL REVIEW
}

LA ESCUELA DEL FUTURO: UNA REVISIÓN CRÍTICA

\author{
CAROLINE OENNING DE OLIVEIRA ${ }^{1}$ \\ ORCID: https://orcid.org/0000-0002-2111-8062 \\ ANDRÉ LUÍS DE OLIVEIRA ${ }^{2}$ \\ ORCID: https://orcid.org/0000-0002-9168-4035
}

PIANGERS, Marcos; BORBA, Gustavo (orgs). A escola do futuro: o que querem (e precisam) alunos, pais e professores. Porto Alegre: Penso, 2019.130 p.

A presente resenha evidencia as ideias do livro $A$ escola do futuro: o que querem (e precisam) alunos, pais e professores, de autoria de Marcos Piangers e Gustavo Borba (2019), publicado pela editora Penso e organizado em 130 páginas. A obra elenca reflexões acerca do processo educativo e tem como propósito a tentativa de promover um diálogo entre alunos, pais e professores, para que se pense sobre a aprendizagem, e no papel da escola, na atualidade e para o futuro. Para tanto, os autores partem de algumas questões que embasam suas discussões: Como será a escola do futuro? O que e como ensinar a esta nova geração que tem, na palma da mão, acesso quase que imediato a qualquer informação? O que esses alunos esperam da escola? E seus pais? Qual o papel dos professores nesse cenário? Tais questões são explanadas, indiretamente, no desenvolvimento da obra, que se apresenta organizada em introdução, seguida por cinco capítulos e considerações finais.

$\mathrm{Na}$ introdução, intitulada Existia a necessidade de a escola existir, Marcos Piangers discorre sobre as muitas mudanças ocorridas no final dos anos 1700, destacando momentos históricos transformadores, bem como o surgimento revolucionário de um sistema de ensino padronizado e acessível para todas as crianças - a escola tradicional -, que existiu e funcionou como base para o mercado de trabalho. Adiante, Piangers inicia uma crítica ao modelo educacional atual - com fortes vestígios tradicionais - uma vez que este tem se tornado obsoleto em uma época caracterizada pela globalização, tecnologias, fácil e rápido acesso à informação e que se encontra em um processo constante de transformação. Nesse sentido, a mensagem introdutória do livro defende que, há cerca de 300 anos, havia a necessidade de a escola existir, contudo, hoje, há a necessidade de a escola se reinventar.

Consideramos válida e inquestionável a mensagem de que a escola do futuro precisa se reinventar a fim de atender as necessidades das novas gerações, distanciando-se do ensino estritamente tradicional. Contudo, nesta seção, Marcos Piangers traz algumas afirmações arriscadas para a área da Educação. Dentre elas, ao mencionar novas metodologias passíveis da escola do futuro, destaca como uma característica a frase "o aprendizado personalizado com menos professores e mais tecnologias" (p. 17, grifos nossos) e, adiante, elenca que "muitas das histórias de sucesso [...] foram desenvolvidas por jovens que largaram seus cursos de graduação. Bill Gates [...], Paul Allen [...], Mark Zuckerberg [...], Steve Jobs [...], Michael Dell [...] e Daniel Ek [...] deixaram a faculdade para empreender" (p. 18), questionando: "de que servirá uma escola que prepara multidões para o desemprego?” (p. 19). Tais excertos, apesar de

\footnotetext{
${ }^{1}$ Universidade Estadual de Maringá. Maringá, PR, Brasil. <oenningcaroline@hotmail.com>

2 Universidade Estadual de Maringá. Maringá, PR, Brasil. <aloprof@gmail.com>
} 
integrarem o contexto de necessidade de mudança do processo educacional, podem incutir no leitor a ideia de que o papel do professor é irrelevante diante das tecnologias, que a formação superior não está relacionada a uma "história de sucesso", bem como a visão de que a escola tem a mera função de preparar para o mercado de trabalho, o que, a nosso ver, consistem em inverdades.

No primeiro capítulo, $A$ escola: uma viagem no tempo, o autor Gustavo Borba destaca alguns aspectos da sociedade, da escola e da rotina dos alunos, que se modificaram no decorrer de um período antecedente à revolução tecnológica até os dias de hoje, no Brasil. Enfatiza que o modelo educacional, em nosso país, sempre esteve atrelado às condições socioeconômicas e explana algumas mudanças marcantes ocorridas entre 1955 a 2018, como o crescimento populacional, o exxodo rural e o surgimento da internet banda larga para a população nos anos 2000. Da mesma forma, o autor afirma que é preciso reconhecer que a escola não é e nunca será um ambiente pronto, mas que está em constante evolução apesar de que em uma velocidade inferior àquela que gostaríamos - e que as características e a rotina dos estudantes também se modificam com o tempo, seja no que concerne à interação na escola, contexto social e/ou principais formas e mídias de comunicação. Conclui que o caminho para o desenvolvimento de um novo paradigma para a educação é compreender os diferentes atores e as relações que são construídas no processo educacional, envolvendo pais, professores e alunos, a partir das tecnologias e da interação coletiva.

A evolução da população e tecnologia no Brasil, a partir da década de 1950, conforme destaca o autor, remete à características oriundas do período em que - com cerca de um século de atraso em relação aos países desenvolvidos - a Revolução Industrial chegou ao Brasil, sendo impulsionada pelos governos de Getúlio Vargas (1930 - 1945 e 1951 - 1954) e Juscelino Kubitschek (1956 - 1961), o que consistiu em um marco para a caracterização da sociedade do século XXI. Nesse sentido, concordamos com o autor em seu posicionamento acerca das relações entre a educação e as condições socioeconômicas do país, refletidas na rotina dos indivíduos. Ainda, é válido ressaltar que os sujeitos, no contexto atual, estão envoltos por situações cada vez mais competitivas e exigentes, o que, muitas vezes, acarreta em expectativas/ansiedade, insegurança, frustrações e na dificuldade de conciliar estudos, trabalho, família, lazer, saúde física e, sobretudo, mental, sendo justificável a necessidade do desenvolvimento de uma educação que envolva a compreensão das potencialidades e limitações desses sujeitos e as relações coletivas e construtivas entre alunos, pais e professores.

O segundo capítulo, Associação de pais aflitos, aponta às inquietações de pais que, rodeados de tanta informação e possibilidades, se sentem inseguros na educação que oferecem aos filhos. O autor Marcos Piangers afirma que, dentre as inseguranças dos pais, se destacam a formação tecnológica (estudo de programação e robótica) e/ou a formação humana (valores sociais, culturais e noções de vida em sociedade) que, segundo o autor, apesar de por vezes se apresentarem distanciadas, são complementares. Ademais, enfatiza que, apesar de se prevalecer uma camada preponderante de pais que buscam a segurança de um sistema educacional estabelecido, há aqueles que buscam métodos experimentais de ensino e/ou sistemas livres de aprendizado, como é o caso do método Kumon, Homeschooling e Unschooling. Para o autor, o mais importante é que os pais incentivem os filhos a serem questionadores, sendo o pensamento crítico e a capacidade de resolução de problemas as habilidades fundamentais na formação educacional para o presente e futuro.

Concordamos, com algumas exceções, que muitos pais não estão satisfeitos com a escola dos filhos, sendo difícil agradar a todos, fato que, infelizmente, tem levado muitas escolas a se tornarem empresas caracterizadas por um meio-termo entre o que a coordenação pedagógica acredita e aquilo que satisfaz os pais. Contudo, Marcos Piangers, ao mencionar os métodos experimentais de ensino e/ou sistemas livres de aprendizado buscados por alguns pais, não engloba de forma esclarecedora as possíveis desvantagens destas escolhas. No caso do Kumon, destaca apenas que "dá ao estudante autonomia e velocidade no aprendizado" (p. 51), para o Homeschooling (educação domiciliar), afirma que apesar de não ser legalizado no Brasil é adotado por mais de 3 mil famílias, em que "pais ou cuidadores coordenam uma série de atividades sem se prender ao currículo escolar" (p. 51, grifos nossos) e para o Unschooling (não escolarizado), atrela aspectos como felicidade, criatividade, experiências e tecnologia, tendo como vantagens "o desenvolvimento do senso de responsabilidade pessoal, automotivação e desejo de aprender" (p. 52), minimizando as desvantagens apresentadas para unicamente "a crítica dos outros" (p. $52)$. 
Em relação ao método Kumon (voltado para o estudo autodidata) é preciso destacar que ele tem como base o método global de ensino, no qual a construção da linguagem está atrelada à percepção/associação global (similar ao reconhecimento de uma pessoa ou objeto, por exemplo), pela memorização e, no caso da matemática, à demasiada repetição de técnicas de cálculo e autoinstrução. $\mathrm{O}$ Homeschooling, se bem efetivado, pode ter como vantagens a autonomia familiar, a formação integral e de determinados valores, resguardo com o bullying e outras pressões sociais, distanciando-se da insatisfação com o ensino escolar. Similarmente, no Unschooling o processo ocorre de acordo com os interesses e vontades do sujeito (criança ou adolescente), que decide o que fazer, sem o direcionamento de um tutor ou dos pais, cabendo a estes últimos apenas motivar e incentivar as escolhas dos filhos. Contudo, quanto a "se prender ao currículo escolar", embora possibilite certa autonomia para abordagens contextualizadas, interdisciplinares e de acordo com as experiências individuais do educando em dado momento, o currículo e os conteúdos escolares sistematizados têm sua importância. Assim, o Homeschooling e o Unschooling, além do fato de não serem legalizados no Brasil e da "crítica dos outros", tem como desvantagens a ausência de meios de controle para o que é considerado fundamental conforme os documentos oficiais para a Educação Básica, que prezam pelo desenvolvimento de saberes intelectuais, políticos e culturais, além de a falta do convívio social necessário ao processo de formação humana, em um possível detrimento de um desenvolvimento integral de senso coletivo, comunitário e colaborativo, uma vez que a escola também exerce um papel social. De qualquer forma, seja na Educação formal ou não formal, em consonância com o tema central deste capítulo, concordamos que o envolvimento dos pais/família/responsáveis é fundamental para o melhor desempenho dos alunos no processo de aprendizagem e formação para a vida.

O terceiro capítulo, intitulado Professores, para onde vamos?, discorre sobre as funções exercidas pelo professor e as competências que precisam ser desenvolvidas para a construção de uma educação de qualidade, voltada para os sujeitos do século XXI. Gustavo Borba elenca a docência como uma profissão muitas vezes desvalorizada e menciona que um dos desafios atuais consiste na atuação dos professores em um ambiente conectado, global, digital e com informação disponível a baixo custo. Ademais, os principais papéis de um professor, nesse contexto, são destacados como o de curador - administrar a construção do conhecimento em meio a informações equivocadas -, mediador - intermediar o diálogo e discussões - e mentor - cuidado com o outro, liderança e cooperação para o desenvolvimento do conhecimento. As competências necessárias, para o autor, devem estar baseadas em um equilíbrio entre teoria e prática e uma compreensão da educação a partir das perspectivas da psicologia, sociologia e currículo, as quais destaca saber projetar, conectar, respeitar as diferenças/personalizar, promover engajamento, promover inovação e o autoconhecimento.

Partilhamos plenamente das afirmações de Gustavo Borba ao discorrer sobre a importância do papel do professor como agente de transformação social e ao destacar sua evidente desvalorização no contexto brasileiro, o que elucida, neste capítulo, alguns dos apontamentos arriscados de Marcos Piangers na seção introdutória, sendo, de certa forma, contraditórios no livro. Em uma conjuntura marcada pelo rápido e fácil acesso à informação, acreditamos ser ainda mais necessária a função docente, uma vez que informação (muitas vezes equivocada ou pseudocientífica) não significa conhecimento ou aprendizado. No entanto, também concordamos que os saberes destacados como "competências para professores", citadas pelo autor, necessitam ser desenvolvidos, dentre outros, para que o professor continue sendo um agente transformador com vistas à uma formação completa e de qualidade para os sujeitos do século XXI.

No quarto capítulo, de título Como alunos queremos uma educação do nosso tempo, Gustavo Borba aponta as características da Geração Z -, nativos digitais que tem chegado, pela primeira vez, no ensino superior -, o tipo de educação que essa geração deseja e necessita, bem como as competências importantes a serem desenvolvidas pelos alunos para a formação no século XXI. A Geração Z é destacada como aquela que nasceu e cresceu em um contexto arraigado pelo uso das tecnologias e tem como características a preocupação com problemas globais e hábitos alimentares, tolerância com o outro e propósito em tudo o que fazem. Segundo o autor, essa geração considera que a melhor forma de aprender é coletiva - com os amigos - e que a "escola dos sonhos" é aquela que vai além dos muros do colégio e que forneça atividades "mão na massa", incluindo tecnologias, visitas culturais e projetos para além da disciplina específica. Por fim, declara como competências necessárias para a formação dos alunos do 
século XXI a responsabilidade socioambiental, cultura ético-estética, senso crítico-reflexivo e resolução de problemas, pensamento computacional, atitude empreendedora e interdisciplinar, comunicação, pensamento projetual e inventivo, criatividade e inovação, interação e colaboração, liderança, autonomia e gestão do conhecimento, habilidades sociais e cross-culturais e fluência tecnológica e digital.

Concordamos com Gustavo Borba, ao expor no capítulo que, para a educação da Geração $Z$, desafiar é o caminho (processo que envolve, além de desafios, feedback imediato e a comemoração do processo para avançar) e engajar é preciso (encorajando a participação e construção coletiva). Ainda, acreditamos que para trilhar este caminho, o uso de metodologias ativas ${ }^{3}$ e o envolvimento de jogos e atividades de interação com as tecnologias e com os outros seres humanos, são essenciais para a superação de diversos aspectos de um método conservador/tradicional de ensino. Quanto ao ensino por competências, citado pelo autor, "a formação por competências é um pressuposto da educação do século XXI" (p. 105), lembramos que o termo "competências" é recorrente em governos neoliberais, sobretudo, em propostas educacionais, cuja intencionalidade subversiva favorece o assujeitamento do indivíduo ao mercado de trabalho, mediante sua força de trabalho e conhecimento técnico para a resolução de problemas pontuais. Por esse motivo, mediante uma compreensão clara e crítica do termo, concordamos que os aspectos mencionados pelo autor como "competências" para a formação do século XXI são importantes, contudo, não sob o viés do ensino por competências. Para tanto, defendemos que a formação de professores e de seus alunos se pautem nos pressupostos da formação crítico-reflexiva, que segundo Alarcão (2010) ocorre no coletivo de professores e no contexto de trabalho destes: a escola.

O quinto e último capítulo, intitulado $A$ escola do futuro, aborda os avanços tecnológicos ocorridos progressivamente nos últimos anos, destacando previsões de inovações futuras dentre as quais se inclui o âmbito escolar. Ao ressaltar a Lei de Moore, Marcos Piangers afirma que já se pode prever que um computador chegará perto da capacidade de um cérebro humano por volta de 2029 e que poderemos plugar nossos cérebros a máquinas inteligentes, multiplicando a inteligência humana em bilhões de vezes, por volta de 2045. Ademais, destaca que a tecnologia tem evoluído gradualmente e que o mesmo vem ocorrendo com o ambiente escolar - primeiramente o uso de CD-ROMS nos anos 90, em seguida lousas interativas nos anos 2000 e hoje realidade virtual e plataformas digitais. Para a escola do futuro, a previsão é que o aprendizado e desenvolvimento dos alunos serão totalmente monitorados, melhorando a atenção dos professores ou de algoritmos inteligentes que aprendem com a experiência de uso. $\mathrm{O}$ autor finaliza evidenciando que a educação personalizada, com professores dedicados a poucos alunos e que sempre teve alto custo, será possível a baixo custo, se a tecnologia for implementada, contudo, que esta jamais substituirá o ser humano e que é de extrema importância que os sistemas educacionais sejam desenvolvidos por profissionais com experiência pedagógica e com a ética profissional que acompanha a formação.

Neste capítulo, nossa percepção foi que a maior parte das discussões estão voltadas aos avanços tecnológicos já decorrentes no mundo e previsões futuras em um âmbito geral, não direcionando ênfase para a escola ou sujeitos da educação frente a estas informações, o que não satisfaz integralmente as expectativas para o título do capítulo - A escola do futuro. Contudo, na parte final, as poucas afirmações de Marcos Piangers acerca do âmbito educacional, de que as tecnologias jamais substituirão o ser humano nas questões morais e éticas ou na criatividade e inovação, ressaltando a importância da profissão docente e experiência pedagógica, são pertinentes e elucidam que a escola do futuro carecerá e, a partir disso, provavelmente, se efetivará da união entre as inovações mais sofisticadas e os seres humanos com seus aspectos insubstituíveis.

Nas considerações finais do livro, sob o título Ao infinito e além..., Gustavo Borba relata o grande aumento da interação e consumo de mídia nos últimos anos, desde a primeira infância, discutindo que isso tem trazido para o meio educacional o desafio engajar alunos e professores. Além disso, traz como reflexões alguns questionamentos - Quais as características que a escola do futuro terá? Quais os dispositivos e mídias que estaremos utilizando em 2050? Como a Geração Z vai formar as próximas gerações, quando estiverem nos espaços mais estratégicos nas organizações? - e conclui mencionando que é impossível responder a qualquer uma dessas perguntas hoje, mas que, certamente, estaremos

${ }^{3}$ Tipo de metodologias que visam o estudante como agente principal e ativo no processo de aprendizagem, distanciando-se da passividade do modelo tradicional de ensino. 
preparados para o futuro, se construirmos um caminho coletivo no presente, que coloque, acima de tudo, a importância da educação.

De modo geral, o livro é interessante e pertinente, já que, diante das mudanças vertiginosas no mundo, se faz necessário superar um processo educacional arcaico e buscar metodologias adequadas para o ensino do século XXI. Os autores abarcam temas sobre a escola, os alunos, pais e professores e as necessidades de cada um deles para uma época que está por vir, em uma linguagem clara e crítica. Recomendamos a leitura para um público alvo variado, integrado por professores (graduados ou em formação), estudantes de pós-graduação em Educação e variadas vertentes das licenciaturas, pais de alunos ou futuros pais, familiares e responsáveis, bem como aos próprios alunos, considerados, pelo autor, residentes e/ou visitantes digitais.

Marcos Piangers é especialista em novas tecnologias, criatividade e inovação, sendo referência sobre paternidade no Brasil. Já deu aulas e palestras em eventos e empresas nacionais, inclusive na TEDx (maior conferência de ideias do mundo) e seus vídeos já ultrapassaram 400 milhões de visualizações. Gustavo Borba é doutor em Engenharia, professor universitário e pesquisador em design com foco para a Educação, atua como diretor de graduação da Unisinos e foi embaixador da TEDx.

\section{REFERÊNCIAS}

ALARCÃO, I. Professores reflexivos em uma escola reflexiva. 7. ed. São Paulo: Cortez, 2010.

PIANGERS, Marcos; BORBA, Gustavo (orgs). A escola do futuro: o que querem (e precisam) alunos, pais e professores. Porto Alegre: Penso, 2019.130 p.

Submetido: $20 / 03 / 2020$

Aprovado: $18 / 06 / 2020$ 